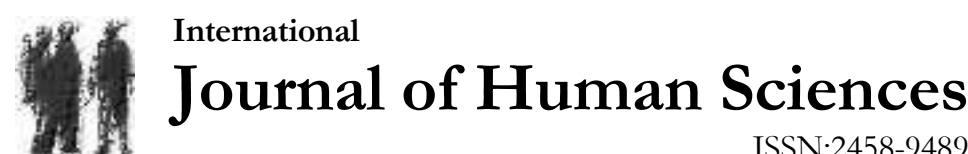

Volume 17 Issue 4 Year: 2020

\section{Does perceived self-regulation affect target commitment?}

\author{
Serhat Turan ${ }^{1}$ \\ Zülbiye Kaçay ${ }^{2}$
}

\begin{abstract}
The aim of this study was to investigate the effect of perceived self-regulation levels on target commitment of secondary school students participating and no-participating in inter-school sports competitions. "General Information Form", "Perceived Self-Regulation Scale (PSRS) and "Goal Commitment Scale (GCS)" were used to collect the data. The sample group consisted of 313 (male $=130$, female $=183$ ) students studying at secondary level. Pearson Moment Correlation test, Manova analysis and simple linear regression analysis were used for data analysis. As a result of the analysis, the main effect of the variables of gender and participating in inter-school sports competitions was not determined to be statistically significant for PSRS and GCS. As a result of the regression analysis, it was determined that perceived self-regulation predicted the target commitment positively and statistically significant. Also, it was determined that there was a positive and significant difference between PSRS and GCS. In this study, it was determined that participating in inter-school sports competitions did not significantly affect perceived selfregulation and target commitment levels. It is recommended that the study should be applied to students who do regular sports and students who do not do regular sports.
\end{abstract}

Keywords: Sports; competition; target commitment; perceived self-regulation.

\section{Introduction}

The education was carried out by using different practices from past to present. It is seen that there are significant differences in today's understanding of education when compared to past. In the traditional education approach, the teacher was at the center and the student was in a passive position. However, in the contemporary education approach, the student is active and in a structuring position. Moreover, in the contemporary education, the individual is the person who questions, researches, thinks critically and constructs knowledge in the learning process. With the development of technology and the increase of mass media, the production of information has accelerated. The rapid dissemination of information has made it easier for students to access information. This situation made it essential for the students to develop their own learning responsibility skills. The students who have learning responsibility set goals for themselves.

\footnotetext{
1 Associate Professor, Balıkesir University, Faculty of Sport Sciences, serhatturan2510@gmail.com iD Orcid ID: 0000-0001-6236-3825

${ }^{2}$ Associate Professor, Çanakkale Onsekiz Mart Universitry, Faculty of Sport Sciences, zzkacay@gmail.com (iD) Orcid ID: 0000-0002-9794-0888
} 
Turan, S., \& Kaçay, Z. (2020). Does perceived self-regulation affect target commitment? Journal of Human Sciences, 17(4), 1047-1053. doi:10.14687/jhs.v17i4.6063

Targets are defined as expressing intentions in detail (Orlich et al., 2010). It is necessary to be determined in order to set the targets and achieve these targets. The determination to reach the target is expressed as the target commitment (Locke \& Latham, 1990). There are two types of objectives as process and performance. While the outcome goals are competition-oriented, performance goals are focused on achieving a standard that exceeds one's previous performance (Burton et al., 2001). Therefore, each individual can set a different target. This situation reveals the individual difference in target commitment (Şenel et al., 2018). It was seen that the individuals who were committed to their goals performed higher in the targets with the same difficulty level compared to the other individuals (Klein \& Wright, 1994). Achieving the goals of individuals requires self-regulation skills.

Self-regulation is expressed as the ability of the individual to consciously direct his/her feelings, emotions, thoughts and behaviors in order to achieve the determined goals (Zimmerman \& Schunk, 2001). The concept of self-regulation is expressed in many ways. However, one of the most important factors in the development of this concept is Albert Bandura's Social Cognitive theory. According to this theory, the individual's behavior occurs as a result of their internal processes and environmental interaction. Thus, the individual has control over his emotions, thoughts and behaviors, can develop alternative strategies, regulate his behaviors and learn various knowledge and skills from the environment (Bandura, 1986). Self-regulation is also expressed as the power to control and direct an individual's emotions, thoughts and behaviors (Zimmerman, 2002). In other words, self-regulation is the change of the individual's inner states and behaviors by the individual herself (Baumeister \& Vohs, 2007). In another definition, self-regulation is defined as organizing information, coding, repetition, focusing on teaching activities and using resources effectively (Schunk, 2001). The concept of self-regulation defined in many different ways; goal setting, following strategies, evaluating strategies and self-evaluation. In order for the individual to perform these stages successfully, they need to have the power and control over their own learning (Karakaş, 2009). The ability of students to take responsibility for learning and to control it is very important, especially at secondary level, so that they can successfully study at their intended university and department. Students' ability to self-regulate is one of the prior condition for this achievement. However, selfregulation skills should be assimilated and developed by the individual for this success. The sport is seen as an effective tool to achieve it. It is seen that sports activities include elements that constitute the stages of self-regulation skills such as having a goal such as winning, containing strategies to achieve this goal, requiring effort for this, existence of rules, controlling behaviors according to rules and evaluating individual's performance in case of success or failure. For this reason, it is thought that sport will contribute to the development of self-regulation skills and thus affect the level of target commitment. The aim of this study was to investigate the effect of perceived self-regulation levels on the target commitment of secondary school students participating and not participating in interschool sports competitions.

\section{Material and Methods}

\subsection{Research Design}

In the research, scanning model was used. Relational scanning model is a research model that aims to determine the presence and / or degree of co-exchange between two or more variables (Karasar, 2013).

\subsection{Research Group}

The research was carried out with students studying at different secondary schools. A total of 313 secondary school students participating and nonparticipating to school sports participated in the study voluntarily (Table 1). 
Turan, S., \& Kaçay, Z. (2020). Does perceived self-regulation affect target commitment? Journal of Human Sciences, 17(4), 1047-1053. doi:10.14687/jhs.v17i4.6063

Table 1. Demographic information of the students participated in the study

\begin{tabular}{llll}
\hline & & Number & Percent (\%) \\
\hline \multirow{2}{*}{ Gender } & Female & 183 & 58.5 \\
\cline { 2 - 4 } & Male & 130 & 41.5 \\
\hline Participation Inter-School & Yes & 155 & 49.5 \\
\cline { 2 - 4 } Sports Competitions & No & 158 & 50.5 \\
\hline & Total & 313 & 100.0 \\
\hline
\end{tabular}

\subsection{Data Collection Tools}

The "General Information Form" prepared to determine the students' gender and participation in inter-school sport competitions was used. Also, in order to determine students' selfregulation skills "Perceived Self-Regulation Scale" developed by Arslan and Gelişli (2015) and "Goal Commitment Scale" which was adapted to Turkish by Şenel and Yildız (2016) were used in the study.

\subsubsection{Perceived Self-Regulation Scale}

The "Perceived Self-Regulation Scale" developed by Arslan and Gelişli (2015) is a 5-point Likert-type scale scored between 1 and 5. The scale comprised of 16 items and 2 sub-dimensions. The first one is the "openness", consisted of items related to students' self-confidences, and the second dimension is the "seeking", which was associated with individuals' quest for their external environment and social life. Cronbach's alpha internal consistency coefficient of the scale was found to be .90. In our study, Cronbach alpha internal consistency coefficient of the perceived selfregulation scale was determined to be .84 .

\subsubsection{Goal Commitment Scale}

It was originally developed by Hollenbeck, Williams, and Klein (1989) in the form of 9 items, later that was revised by Kein et al. (2001), the Goal Commitment Scale has a single dimension and 5 item. It is a five-point Likert-type scale scored between"strongly disagree" (1) and "strongly agree" (5). Also it was adapted to Turkish by Şenel and Yildı (2016). The internal consistency coefficient was determined as 0.74 by Şenel and Yıldız (2016) in the adaptation study. In our study, the Cronbach alpha internal consistency coefficient of the target commitment scale was found to be .71 .

\subsection{Data Analysis}

SPSS 20 package program was used for data analysis. In order to determine whether the distribution of the data is normal or not, the skewness and kurtosis values were examined and Shapiro-Wilk's and Kolmogorov-Smirnov tests were performed. As a result of the evaluations, it was determined that the data were suitable for normal distribution. MANOVA was conducted in order to determine the main effects of gender and participation in school sports variables on PSRS (Perceived Self-Regulation Scale) and GCS (Goal Commitment Scale). In addition, Pearson Moment Correlation test was used to determine the relationship between PSRS and GCS. A simple linear regression analysis was conducted to determine how much the perceived self-regulation skill predicted the target commitment. It was determined that the necessary prerequisites for the analysis were met. Later, while the perceived self-regulation variable was entered in the analysis as an independent variable, target adherence was entered as the dependent variable. In the study, the significance level was determined as $\mathrm{p}<.05$ and $\mathrm{p}<.01$.

\section{Results}

In this section, the findings obtained as a result of the analysis of the information collected are included. 
Turan, S., \& Kaçay, Z. (2020). Does perceived self-regulation affect target commitment? Journal of Human Sciences, 17(4), 1047-1053. doi:10.14687/jhs.v17i4.6063

Table 2. The results of the MANOVA for PSRS and GCS according to Gender and Participation in Inter-School Sport Competitions

\begin{tabular}{|c|c|c|c|c|c|c|c|}
\hline Independent I & Variables & Value & $\mathbf{F}$ & $\begin{array}{l}\text { Hypothesis } \\
\text { df }\end{array}$ & Error & $\mathrm{p}$ & $\eta^{2}$ \\
\hline \multirow{4}{*}{ Gender } & Pillai's Trace & .016 & $2.476 \mathrm{~b}$ & 2.000 & 308.000 & .086 & .016 \\
\hline & Wilks' Lambda $(\lambda)$ & .984 & $2.476 \mathrm{~b}$ & 2.000 & 308.000 & .086 & .016 \\
\hline & Hotelling's Trace & .016 & $2.476 \mathrm{~b}$ & 2.000 & 308.000 & .086 & .016 \\
\hline & Roy's Largest Root & .016 & $2.476 \mathrm{~b}$ & 2.000 & 308.000 & .086 & .016 \\
\hline \multirow{4}{*}{$\begin{array}{l}\text { Participation } \\
\text { in Inter- } \\
\text { School Sports } \\
\text { Competitions }\end{array}$} & Pillai's Trace & .007 & $1.091 \mathrm{~b}$ & 2.000 & 308.000 & .337 & .007 \\
\hline & Wilks' Lambda $(\lambda)$ & .993 & $1.091 \mathrm{~b}$ & 2.000 & 308.000 & .337 & .007 \\
\hline & Hotelling's Trace & .007 & $1.091 \mathrm{~b}$ & 2.000 & 308.000 & .337 & .007 \\
\hline & Roy's Largest Root & .007 & $1.091 \mathrm{~b}$ & 2.000 & 308.000 & .337 & .007 \\
\hline
\end{tabular}

p>.05

Multivariate analysis of variance (MANOVA) was used to examine the total scores of the PSRS a TLS (Targeting Scale). The total scores of PSRS and GCS were entered as model dependent variables. Gender (female, male) and participation in school sports (yes, no) variables were entered as independent variables in the model. When Manova results were examined, gender $(\lambda=.984, \mathrm{~F}(2$, $\left.308)=2.476, \mathrm{p}=.086, \eta^{2}=.016\right)$ and participation in school sports $(\lambda=.993, \mathrm{~F}(2,308)=1.091, \mathrm{p}=$ $\left..337, \eta^{2}=.007\right)$ were not found to be significant for the main effect of PSRS and GCS. A simple linear regression analysis was carried out to estimate the goal setting scale (GCS) by the PSRS and the results are presented in Table 3.

Table 3. Results of regression analysis for predicting the goal setting scale

\begin{tabular}{llllll}
\hline The predictors & $\mathbf{B}$ & Std. Error & $\boldsymbol{\beta}$ & $\mathbf{t}$ & $\mathbf{P}$ \\
\hline Constant & 1.786 & .259 & & 6.904 & $.000^{*}$ \\
\hline PSRS & .620 & .069 & .457 & 9.051 & $.000^{*}$ \\
\hline $\mathbf{F}$ & & 81.927 \\
\hline $\mathbf{R}$ & \multicolumn{5}{c}{$.457^{*}$} \\
\hline $\mathbf{d z l t \mathbf { R } ^ { 2 }}$ & & \multicolumn{3}{c}{.21} \\
\hline${ }^{*}<.01$ & & \multicolumn{3}{c}{ PSRS: Perceived Self-Regulation Scale }
\end{tabular}

In Table 3, simple linear regression analysis was performed. As a result of the analysis, it was determined that perceived self-regulation predicted the target commitment positively and it was statistically significant $\left(\mathrm{F}=81.927, \mathrm{p}<.01, \mathrm{R}^{2}=.21\right)$. As a result of simple linear regression analysis, it was determined that perceived self-regulation explained $21 \%$ of the total variance of target commitment. Also, a positive and significant relationship was determined between PSRS and GCS in Table $3(\mathrm{r}=.457, \mathrm{p}<.01)$.

\section{Discussion and Conclusion}

In this study, the effect of perceived self-regulation levels of secondary school students participating and no- participating in sports competitions on target commitment was examined.

In our study, a positive and significant relationship was determined between perceived selfregulation and target commitment. In addition, it was determined that perceived self-regulation predicted target commitment positively and statistically significant. It was found that perceived selfregulation explained $21 \%$ of the total variance of target commitment. Setting self-regulation skills is very important (Pintrich, 2000). Therefore, self-regulation skills play an important role in setting goals 
Turan, S., \& Kaçay, Z. (2020). Does perceived self-regulation affect target commitment? Journal of Human Sciences, 17(4), 1047-1053. doi:10.14687/jhs.v17i4.6063

and acting with commitment. Individuals with self-regulation skills control, direct their behavior, follow their own cognitive processes, and become aware of their abilities to achieve their goals.

As a result of the analysis conducted on the perceived self-regulation levels of secondary school students participating and non-participating in sports competitions, there was no significant difference between the groups. When the literature review was made, it was determined that some studies were not similar to our study (Ommundsen, 2006; Oaten \& Cheng, 2006; Olson, 2009; Kaplan, 2014). In a study, self-regulation skills were found to have positive effects on performance (Ommundsen, 2006). In another study, it was reported that the average self-regulation score of the individuals doing regular sports was significantly higher than those who did not do regular sports (Kaplan, 2014). Moreover, the researchers found that exercise improves self-regulation skills (Oaten \& Cheng, 2006). They underwent a two-month physical exercise program to develop self-regulation skills and stated that as a result of this program a significant progress was made in the control of emotions and the regulation of behaviors. On the other hand, some researchers examined how preservice physical education teacher candidates use self-regulation skills and self-regulatory abilities in their learning. As a result of this study, it was found that there were significant relationships between students' weekly work and self-regulation skills (Olson, 2009). In the present study, both groups participate in physical education and sports classes as a compulsory subject in the curriculum. Therefore, the research group consists of athletes. Therefore, it is thought that there is no statistically significant difference in the study. However, when the average scores of the students were examined, it was determined that there was a difference in favor of the students who participated in sports competitions between schools, although it was not statistically significant.

In our study, it was determined that self-regulation skills did not show a significant difference according to gender. When the relevant literature was examined, it was seen that some studies were conducted in which self-regulation levels were compared by gender (Alıc1 \& Altun, 2007; Gömleksiz \& Demiralp, 2012; Kaplan, 2014; Şahin, 2015). In a study conducted on preservice physical education teachers, it was found that the self-regulation scores of female students were significantly higher than the male students (Kaplan, 2014). In some studies, conducted on different sample groups, it was found that the mean scores of self-regulation of female students were significantly higher than the male students (Alıcı \& Altun, 2007; Gömleksiz \& Demiralp, 2012).

Studies show that female students are stronger emotionally and this result thought to be caused by the fact that they guide their feelings, emotions, thoughts and behaviors better than men. In a study conducted for physical education teacher candidates, it was found that there was no significant difference between male and female students (Şahin, 2015). The results of our study parallels with the results of this study. This study suggests that the student both group is aware of their responsibilities as they study at the high academic level colleges of the region. In this case, it is thought that there is no significant difference between self-regulation levels of female and male students.

In our study, no significant difference was determined between the target commitment levels of secondary school students participating and non-participating in sports competitions. As a result of the review of the related literature, no study was found in which target commitment was investigated at the secondary level. In a study conducted on high school students, it was determined that there was no significant difference between target commitment levels of individuals doing and not doing sports (Çekceoğlu, 2019). The results of our study are similar to this study. In a study, it was determined that the mean scores of the target participants were significantly higher than those who did not do sports (Öntürk et al., 2018). In our study, it was thought that taking the physical education and sports course included in the curriculum as a compulsory course affected the absence of a significant difference between the groups. Because sports contribute to the development of many skills such as self-regulation, self-esteem, goal setting (Locke \& Latham, 1984) and self-confidence that will affect the target commitment of individuals. Therefore, there was no significant difference between the students who participated in sports competitions between schools and those who did 
not. However, it was found that the average scores of students who participated in sports competitions between schools were higher than those who did not participate.

In our study, it was determined that target commitment levels did not show a significant difference according to gender. When the literature was examined, some studies showed that the target commitment was examined in terms of gender and there were significant differences between the groups (Jiang, 2016). In a study, a significant difference was found in favor of female students between the target commitment levels of male and female high school students (Çekceoğlu, 2019). The reason for this, is the earlier maturation of women and the development of decision-making mechanisms. In some studies, it was reported that there was no significant difference between genders in terms of target commitment (Öntürk et al., 2018; Salim, 2018). The results of these studies are similar to the results our study. Studying at schools that are academically close to each other in both gender groups provides them with similar education. This situation is thought to have an effect on the high level of awareness of both gender groups and in setting realistic goals.

In the study, it was determined that participation in sports competitions between schools did not have a statistically significant effect on perceived self-regulation and target commitment levels. However, it was determined that perceived self-regulation was a good predictor of target commitment. It is recommended to apply the future studies to the students who do regular sports and those who do not, and to be carried out by using different variables such as sports age, sports branch, education level of the family and socioeconomic status.

\section{References}

Alic1, B. \& Altun, S. (2007). Is there a difference in high school students' self-regulatory and metacognitive skills towards mathematics with respect to gender, level, and field? Çukurova University Journal Institute of Social Sciences, 16 (1): 33-44.

Arslan, S. \& Gelişli, Y. (2015). Development of perceived self-regulation scale: validity and reliability study. Sakarya University Journal of Education, 5 (3): 67-74. DOI: http://dx.doi.org/10.19126/suje.91303.

Bandura, A. (1986). Observational learning. A. Bandura (Ed), Social foundations of thought and action: A social cognitive theory (ss.169-195) içinde. Englewood Cliffs, NJ: Prentice-Hall.

Baumeister, R.F. \& Vohs, K.D. (2007). Self-regulation, ego-depletion, and motivation. Social and Personality Psychology Compass, 1 (1): 115-128.

Burton, D., Naylor, S. \& Holliday, B. (2001). Goal setting in sport: Investigating the goal effectiveness paradox. R. Singer, H. Hausenblas, \& C. Janelle (Eds.), Handbook of sport psychology, $497-$ 528.

Çekceoğlu, H. (2019). Investigation of resilience and goal commitment levels of high school students doing sports or not doing sports. Master's thesis. Turkey: Karamanoğlu Mehmetbey University.

Gömleksiz, N.M. \& Demiralp, D. (2012). An assessment of prospective teachers' views toward their self-regulated learning skills in terms of several variables. Gaziantep University Journal of Social Sciences, 11 (3): 777 -795.

Hollenbeck, J.R., Williams, C.L. \& Klein, H.J. (1989). An empirical examination of the antecedents of commitment to difficult goals. Journal of Applied Psychology, 74, 18-23.

Jiang, Z. (2016). Emotional intelligence and career decision-making self-efficacy: mediating roles of goal commitment and professional commitment. Journal Of Employment Counseling, 53 (1): 30-47.

Kaplan, E. (2014). Self-regulation in students of physical education and sport teaching departments: scale adaptation work. Master's thesis. Turkey: Mediterranean University. 
Turan, S., \& Kaçay, Z. (2020). Does perceived self-regulation affect target commitment? Journal of Human Sciences, 17(4), 1047-1053. doi:10.14687/jhs.v17i4.6063

Karakaş, N. (2009). The effects of portfolios used in the process of assessment of mathematıcs lesson on 5th grade students' self regulation skills, cognitive strategy use and views. Master's thesis. Turkey: Yıldız Technical University.

Klein, H.J., Wesson, M.J., Hollenbeck, J.R., Wright, P.M. \& Deshon, R.P. (2001). The assessment of goal commitment: A measurement model meta-analysis. Organizational Behavior and Human Decision Processes, 85 (1): 32-55. https://doi.org/10.1006/obhd.2000.2931

Klein, H.J. \& Wright, P.M. (1994). Antecedents of goal commitment: An empirical examination of personal and situational determinants. Journal of Applied Social Psychology, 24: 95-114.

Locke, E.A. \& Latham, G.P. (1984). Goal-setting: A motivational technique that works. Englewood Cliffs, NJ: PrenticeHall.

Locke, E.A. \& Latham, G.P. (1990). A theory of goal setting and task performance. Englewood Cliffs, NJ: Prentice Hall International.

Oaten, M. \& Cheng, K. (2006). Longitudinal gains in self-regulation from regular physical exercise. British Journal Of Health Psychology, 11: 717-733.

Olson, T.D. (2009). Assessment of preservice physical education teacher education (pete) students' self-regulation: 1mplications for teacher foundational enhancement. UMI 3390823 Copyright by ProQuest LLC.

Ommundsen, Y. (2006). Pupils' self-regulation in physical education: the role of motivational climates and differential achievement goals. European Physical Education Review 12: 289.

Orlich, D.C., Harder, R.J., Callahan, R.C., Trevisan, M.S. \& Brown, A.H. (2010). Teaching strategies: a guide to effective instruction, (9th edition). Wadsworth: Australia $\bullet$ Brazil $\bullet$ Japan $\bullet$ Korea $\bullet$ Mexico $\bullet$ Singapore $\bullet$ Spain $\bullet$ United Kingdom $\bullet$ United States

Öntürk, Y., Bingöl, E., Göksel, A.G. \& Çağlayan, A. (2018). Investtgatıon of corporate target donations of administratıve staff at university. Journal of Social And Humanities Sciences Research (JSHSR), 5 (30) 4016-4021.

Pintrich, P.R. (2000). The role of goal orientation in self-regulated learning. In Boekarters M., Pintrich P.R. \& Zeidner M. (Eds), (2005, 452-502) Handbook of Self-Regulation, San Diego: Academic Press.

Salim, E. (2018). Reviewing problem solving skills and goal commitmrnt among orienteering athletes. Master's thesis. Turkey: Muğla S1tk1 Koçman University.

Schunk, D.H. (2001). Self-Regulation through goal setting. ERIC/CASS Digest ED462671.

Şahin, F.T. (2015). A study into self-regulation sufficiencies of the students attending to the college physical education and sport. International Journal of Science Culture and Sport (IntJSCS). Special Issue 4: 425-438.

Şenel, E. \& Yıldız, M. (2016). Goal commitment scale: turkish adaptation, validity and reliability in students studying in the field of physical education and sport. CBU Journal of Physical Education and Sport Sciences, 11(2): 58-65.

Şenel, E., Yıldız, M. \& Can, S. (2018). The path to success in education: moral attitude, goal commitment, and cheating tendency. 2nd International Turkıc World Congress on Education and Social Sciences 7-8 December, Antalya-TURKEY.

Zimmerman, B.J. (2002). Becoming a self-regulated learner: an overview. Theory Into Practice, 41 (2): 64-70.

Zimmerman, B.J. \& Schunk, D.H. (Eds.). (2001). Self-regulated learning and academic achievement: Theoretical perspectives. USA: Lawrence Erlbaum A 